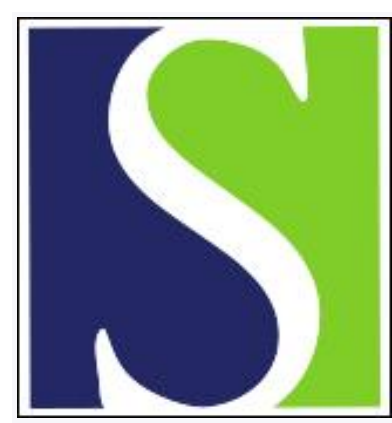

Scand J Work Environ Health 1991;17(2):139-144

https://doi.org/10.5271/sjweh.1723

Issue date: Apr 1991

Evaluation of serum aminoterminal propeptide of type III procollagen as an early marker of the active fibrotic process in asbestos-exposed workers.

by Cavalleri A, Gobba F, Bacchella L, Ferrari D

Affiliation: Chair of Occupational Medicine, University of Modena, Italy.

This article in PubMed: www.ncbi.nlm.nih.gov/pubmed/2047816 


\title{
Evaluation of serum aminoterminal propeptide of type III procollagen as an early marker of the active fibrotic process in asbestos-exposed workers
}

\author{
by Alessandro Cavalleri, MD, ${ }^{1}$ Fabriziomaria Gobba, MD, ${ }^{1}$ Luisa Bacchelia, MSc, ${ }^{2}$ \\ Davide Ferrari, MD, ${ }^{1}$
}

\begin{abstract}
CAVALLERI A, GOBBA F, BACCHELLA L, FERRARI D. Evaluation of serum aminoterminal propeptide of type III procollagen as an early marker of the active fibrotic process in asbestos-exposed workers. Scand J Work Environ Health 1991;17:139-44. In an evaluation of the possibility of type III procollagen N-terminal propeptide (PIIINP) being an early marker of the active fibrotic process in asbestosexposed workers, 91 asbestos workers had higher serum PIIINP concentrations than 108 referents. In 24 workers exposed to low levels of airborne asbestos, the serum PIIINP was higher than in the referents but lower than in an exposed group with higher exposure; furthermore a significant correlation $(r=0.63)$ was found between serum PIIINP and individual cumulative exposure. These data suggest a dose-effect relationship between asbestos exposure and PIIINP serum concentration. In addition workers with a reduced pulmonary function had higher PIIINP values than the referents or the exposed workers with normal pulmonary function. The serum PIIINP levels were related to asbestos exposure even at low airborne concentrations and may represent an early biological marker of impending fibrotic process induced by asbestos.
\end{abstract}

Key terms: asbestos cement, asbestos-induced fibrosis, biological marker.

The early phase of the pulmonary fibrotic process induced by asbestos inhalation is represented by alveolitis (1). This stage may be detected by bronchoalveolar lavage (BAL) or by Gallium-67 scanning $(1,2)$. These diagnostic procedures are not however suitable as monitoring strategys for exposed workers that are apparently healthy. On the other hand, at this stage of the disease radiographic examination, currently the adopted method for monitoring the health of exposed workers, is usually negative $(3,4)$, and pulmonary function tests are not necessarily diagnostic, at least on an individual basis (5). Therefore new screening methods able to detect the early appearance of asbestos-induced fibrotic changes in exposed workers are needed, especially since early or active fibrosis may be more easily halted or delayed by preventive measures than later stages of scarring.

The assay of biochemical indices of fibrogenic activity represents a promising method for determining the appearance of the alveolitic process. In cases of cryptogenic fibrosing alveolitis, Bateman et al (6) demonstrated an increase in type III collagen content in areas of active lung fibrogénesis. On the contrary, this isotype of collagen was significantly reduced in the lungs of patients who had died of fibrosing alveolitis

\footnotetext{
I Chair of Occupational Medicine, University of Modena, Modena, Italy.

2 Department of Nuclear Medicine, Fondazione Clinica del Lavoro, Pavia, Italy.
}

Reprint requests to: Professor A Cavalleri, Cattedra di Medicina del Lavoro, Universita' di Modena, v Campi 287, I-41100 Modena, Italy.
(7). A similar phenomenon was evidenced in the lungs of rats exposed to silica (8), in skin scars (9), and in alcoholic liver fibrosis (10). An increase in type III collagen therefore seems to represent a marker of the early phase of an active fibrotic process, whereas later stages are characterized by a progressive increase in the amount of type I collagen accompanied by a parallel decrease in type III.

The determination of collagen type III in pulmonary tissues requires bioptic sample collection and, therefore, is possible only in experimental studies or as a diagnostic procedure in selected cases. An indirect biochemical index of type III collagen synthesis is available, however, since the extension peptides of procollagen III, the precursor of collagen, are cleaved in stoichiometric amounts during the conversion of procollagen into collagen (11).

The N-terminal extension peptide of procollagen type III (PIIINP) may be easily measured in serum and other body fluids, and its level in serum is closely related to the content of type III collagen in pulmonary tissue (12). Increased levels of PIIINP have been found in BAL fluids during the early active stage of fibrosing alveolitis (13) and in sarcoidosis (14) and asbestos alveolitis, in the latter case in both animals and exposed workers (15). Furthermore an increased level of PIIINP was observed in the serum of a patient with cryptogenic fibrosing alveolitis (7). Nevertheless a recent study failed to demonstrate a significantly higher level of serum PIIINP in workers with asbestosis than in a group of asbestos-exposed workers without radiological signs of fibrosis (16). Workers exposed to low 
levels of asbestos fiber were found to have significantly higher values of serum PIIINP than unexposed referents, the concentrations being more elevated in subjects with reduced forced vital capacity (17). A dosedependent increase in serum PIIINP levels, starting with very low levels of exposure to airborne asbestos fiber, has also been demonstrated (17).

We therefore decided to study a large group of workers who had been exposed to asbestos for various lengths of time and either had no radiological signs of asbestosis or the signs were very early ones. The aim of the investigation was to evaluate a possible doseeffect and dose-response relationship between airborne asbestos and serum PIIINP levels and the relation of the serum PIIINP level to pulmonary function values. In order to assess the specificity and reliability of the determination of PIIINP in serum as a parameter for the biological monitoring of workers exposed to asbestos fibers, we also took smoking habits and alcohol consumption into consideration.

\section{Subjects and methods}

\section{Subjects}

Ninety-eight currently exposed workers, representing the entire asbestos-exposed work force of three small factories producing asbestos cement items, were considered eligible for the study. Because of abnormal serum aminotransferase levels or a history of viral hepatitis or drug addiction seven subjects were excluded from the study. A careful occupational history was taken by questionnaire.

Table 1. Airborne asbestos fiber levels (fibers $/ \mathrm{ml}$ ) observed between 1976 and 1986 and the percentage of crocidolite and chrysotile.

\begin{tabular}{lcccc}
\hline & \multicolumn{1}{c}{1976} & $1982^{\mathrm{a}}$ & $1983^{\mathrm{a}}$ & $1986^{\mathrm{a}}$ \\
\cline { 2 - 5 } & \multicolumn{4}{c}{ Fibers/ml (range) } \\
\cline { 2 - 5 } $\begin{array}{l}\text { Stationary sampling } \\
\text { Personal sampling }\end{array}$ & $\begin{array}{c}0.1-11.5 \\
\ldots\end{array}$ & $0.1-0.96$ & $0.2-1.04$ & $0.01-0.3$ \\
& $0.1-0.81$ & $0.37-1.38$ & $0.1-3.8$ \\
\cline { 2 - 5 } & Percentage of the total amount of asbestos \\
\cline { 2 - 5 } $\begin{array}{l}\text { Crocidolite } \\
\text { Crysotile }\end{array}$ & 20 & $25-30$ & 25 & $\begin{array}{c}0-30 \\
70-100\end{array}$ \\
\hline
\end{tabular}

a Determinations performed according to 1979 AlA reference method (18)
A reference group of 120 healthy referents, not occupationally exposed to asbestos or other dusts or toxic substances, was selected. However 12 subjects were excluded because of elevated serum aminotransferase values, and therefore the final reference group consisted of 108 subjects.

\section{Assessment of asbestos exposure}

Asbestos exposure was evaluated by stationary or personal sampling or both, according to the reference method of the Asbestos International Association (AIA) (18). Table 1 shows the results of environmental monitoring in the three factories over 10 years (1976-1986). In 1976 the AIA method was not yet available; however the measuring procedure we used at that time involved only minor technical differences as compared with the AIA method. Therefore the results obtained with the previous method were included in the study. Chrysotile represented the main fiber used in the production, but a relatively low crocidolite percentage ( $0-30 \%$ of total asbestos) was also present.

According to the time-weighted average (TWA) of the asbestos levels observed for airborne asbestos during different periods of environmental monitoring for 52 of the exposed subjects, a classification into two groups was possible. Group 1 consisted of subjects with low exposure (TWA of $\leq 0.2$ fibers $/ \mathrm{ml}$ ), and group 2 comprised subjects with higher exposure (TWA of $>0.2$ fibers $/ \mathrm{ml}$ ). Due to insufficient data or repeated job changes no reliable quantification of the exposure was available for 39 workers. These workers were included in the whole study sample but not subdivided into the two groups.

For 21 workers, all exposed for less than five years and repeatedly monitored by personal air sampling, it was also possible to estimate an individual cumulative "dose" expressed as fibers/milliliter $\times$ years (19).

\section{Medical history}

A medical and occupational history was obtained from all of the participants, who were also given a physical examination. The main characteristics, including age and smoking habits, of the exposed workers and the referents are presented in table 2 . The exposed groups

Table 2. Main characteristics of the examined subjects.

\begin{tabular}{|c|c|c|c|c|c|c|c|c|}
\hline \multirow{3}{*}{ Group } & \multirow{3}{*}{ Number } & \multirow{2}{*}{\multicolumn{2}{|c|}{$\begin{array}{c}\text { Age } \\
\text { (years) }\end{array}$}} & \multicolumn{3}{|c|}{ Smoking habits ${ }^{a}$} & \multirow{2}{*}{\multicolumn{2}{|c|}{$\begin{array}{l}\text { Months } \\
\text { of exposure }\end{array}$}} \\
\hline & & & & \multirow{2}{*}{ Number } & \multicolumn{2}{|c|}{ Cigarettes/day } & & \\
\hline & & Mean & SD & & Mean & SD & Mean & SD \\
\hline Reference & 108 & 39.5 & 9.6 & 52 & 18.2 & 8.5 & - & $\cdot$ \\
\hline Exposed & 91 & 36.6 & 12.1 & 57 & 20.6 & 10.5 & 99.3 & 93.3 \\
\hline $\begin{array}{l}\text { Group } 1 \text { (exposure } \leq 0.2 \text { fibers } / \mathrm{ml} \text { ) } \\
\text { Group } 2 \text { (exposure }>0.2 \text { fibers } / \mathrm{ml} \text { ) }\end{array}$ & $\begin{array}{l}24 \\
28\end{array}$ & $\begin{array}{l}36.9 \\
30.5\end{array}$ & $\begin{array}{r}13.3 \\
8.9\end{array}$ & $\begin{array}{l}15 \\
19\end{array}$ & $\begin{array}{l}20.6 \\
20.4\end{array}$ & $\begin{array}{r}14.8 \\
9.0\end{array}$ & $\begin{array}{r}107.0 \\
41.3\end{array}$ & $\begin{array}{l}81.9 \\
57.6\end{array}$ \\
\hline
\end{tabular}

a Workers that had given up smoking for less than five years were included in the current smokers group. 
did not differ from the referents as to age or smoking habits. None of the participants showed any obvious skin scarring at the time of the study. To exclude incidental liver or collagen diseases, blood samples were taken for the determination of erythrocyte and leucocyte counts, hemoglobin, packed cell volume, serum alanine aminotransferase, serum aspartate aminotransferase, erythrocyte sedimentation rate, rheumatoid factor, and protein electrophoresis. Serum creatinine measurement and urine analysis were also undertaken to rule out kidney disease (12). The analyses were all performed with the currently adopted laboratory methods.

\section{Pulmonary function testing}

Eighty exposed workers performed a lung function test administered by experienced technicians with a calibrated rubber sealed spirometer $\left(\right.$ Vitalograph $\left.{ }^{\circledR}\right)$. Forced vital capacity (FVC) and forced expiratory volume in $1 \mathrm{~s}\left(\mathrm{FEV}_{1.0}\right)$ were recorded and compared to the reference values of Cotes (20). The results are reported as the percentage ratio between the observed values and the mean reference values.

\section{Chest Radiographs}

All of the referents underwent standard chest radiography. No cases of current lung disease were found. For all of the asbestos workers standard high-kilovoltage posteroanterior films were obtained. The chest radiographs were blindly classified according to the 1980 ILO International Classification of Radiographs of Pneumoconiosis (21) by a radiologist with extensive experience with occupational lung diseases.

\section{Serum analysis of aminoterminal propeptide of type III procollagen}

For the PIIINP measurement serum samples were separated within $2 \mathrm{~h}$ of venipuncture and stored at $-20^{\circ} \mathrm{C}$ until determination, which, in all cases, was performed within the next two months. [Rhode et al showed a substantial stability of PIIINP serum levels for at least one year (10)]. The serum PIIINP levels were determined according to the radioimmunoassay method of Rhode et al (10). Commercially available RIA-gnost Prokollagen-III Peptide Kits ${ }^{\circledast}$ (Behring, SpA, Scoppito, L'Aquila, Italy) were used. At three different PIIINP concentrations, the mean recovery ranged from 89 to $104 \%$, and the interassay coefficient of variation from 7 to $15 \%$.

\section{Results}

For group 1 the airborne levels of asbestos fibers (median count 0.1 fibers $/ \mathrm{ml}$ ) were well below the TWA of the threshold limit value of the American Conference of Governmental Industrial Hygienists (22); also for group 2 the exposure was not very elevated (median count 0.9 fibers $/ \mathrm{ml}$ ). The workers in group 1 were however older and had been exposed to asbestos for a longer time than group 2 (table 2). This difference was due to a more rapid turnover among the workers in tasks with higher exposure levels.

The serum PIIINP levels of the exposed workers and the referents are presented in table 3 . For both the entire exposed group and each of the subgroups separately the PIIINP concentration was significantly higher than for the reference group. Furthermore the workers in group 2, which was exposed to higher levels of asbestos, if even for a short period of time, showed the highest values of PIIINP in serum, the mean difference versus group 1 being significant $(P<0.005)$.

No significant correlations were found between the PIIINP values and pleural changes (pleural fibrosis, calcifications and pleural plaques).

The observed results were not due to age differences or tobacco or alcohol consumption since these variables, which were similar for the exposed workers and the referents, did not correlate significantly with the serum PIIINP levels. It should be stressed that all of the examined workers were light-to-moderate drinkers. The data then suggest that even asbestos exposure to low amounts of fibers is able to induce a significant increase in the serum levels of PIIINP and that this increase may be dose-dependent. This hypothesis was corroborated in a comparison of the serum PIIINP concentration and individual cumulative exposure "dose" (fibers/ml $\times$ years) in a subgroup of 21 workers monitored by personal sampling. A significant correlation was found $(r=0.55, P<0.005)$. When the individual cumulative doses of asbestos were expressed on a logarithmic scale, the correlation improved further $(r=0.63, P<0.005)$ (figure 1).

No correlation was found between the PIIINP values and subjective respiratory symptoms or objective pulmonary signs.

Only five workers showed radiographic signs of fibrosis [ $1 / 0$ or more according to the ILO classification (21)]. The serum PIIINP values of these subjects did not differ from those of exposed workers without radiographic signs [mean 15.3 (SD 2.06) versus mean 16.2 (SD 4.97)].

The serum PIIINP values of the exposed workers, classified according to the results of the pulmonary

Table 3. Type III procollagen $\mathrm{N}$-terminal propeptide (PIIINP) in the serum of the exposed workers and the referents.

\begin{tabular}{|c|c|c|c|c|c|}
\hline \multirow{2}{*}{ Group } & \multirow{2}{*}{ Number } & \multicolumn{3}{|c|}{ PIIINP (ng/ml) } & \multirow{2}{*}{$\begin{array}{c}\text { Significance } \\
\text { of difference } \\
\text { versus } \\
\text { referents }\end{array}$} \\
\hline & & Mean & $S D$ & Range & \\
\hline Referents & 108 & 12.0 & 3.61 & $6.5-25$ & . \\
\hline \multicolumn{6}{|l|}{ Exposed ${ }^{a}$} \\
\hline $\begin{array}{l}\text { Group } 1 \\
\text { Group } 2\end{array}$ & $\begin{array}{l}24 \\
28\end{array}$ & $\begin{array}{l}15.3 \\
19.2\end{array}$ & $\begin{array}{l}3.4 \\
5.6\end{array}$ & $\begin{array}{r}9.0-25 \\
12.0-32\end{array}$ & $\begin{array}{l}P<0.005 \\
P<0.005\end{array}$ \\
\hline All & 91 & 16.0 & 4.79 & $7.5-32$ & $P<0.001$ \\
\hline
\end{tabular}

a Significance of difference between group 1 vs group 2: $\mathrm{P}<0.005$. 


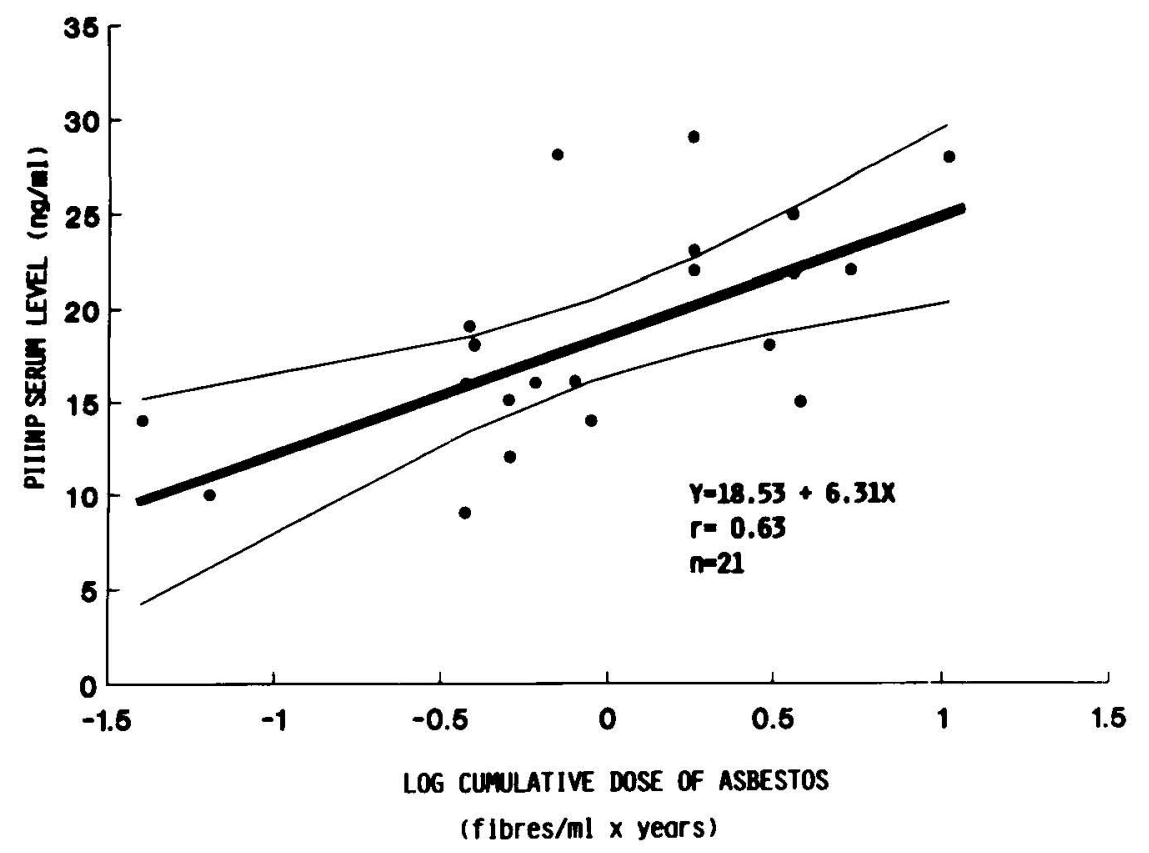

Figure 1. Correlation between serum PIIINP levels $(\mathrm{ng} / \mathrm{ml}$ ) and individual cumulative exposure to asbestos (fibers $/ \mathrm{ml} \times$ years) expressed on a logarithmic scale.

Table 4. Mean concentration of type III procollagen $\mathrm{N}$-terminal propeptide (PIIINP) in the serum of the exposed workers, classified according to their pulmonary function testing results $\left(F V C=\right.$ forced vital capacity; $F E V_{1.0}=$ forced expiratory volume in $1 \mathrm{~s})$.

\begin{tabular}{|c|c|c|c|c|}
\hline & \multirow{2}{*}{$\begin{array}{l}\text { Number } \\
\text { of } \\
\text { workers }\end{array}$} & \multicolumn{2}{|c|}{ PIIIP (ng/ml) } & \multirow{2}{*}{$\begin{array}{l}\text { Significance of } \\
\text { the difference }\end{array}$} \\
\hline & & Mean & $\mathrm{SD}$ & \\
\hline $\begin{array}{l}\text { FVC } \geq 100 \% \\
\text { FVC }<100 \% \\
\text { FEV }_{1.0} \geq 100 \% \\
\text { FEV }_{1.0}<100 \%\end{array}$ & $\begin{array}{l}47 \\
33 \\
43 \\
37\end{array}$ & $\begin{array}{l}15.2 \\
17.4 \\
15.1 \\
17.5\end{array}$ & $\begin{array}{l}4.8 \\
5.0 \\
4.9 \\
4.9\end{array}$ & $\begin{array}{l}P<0.05 \\
P<0.05\end{array}$ \\
\hline
\end{tabular}

Table 5. Dose-response relationship for the concentration of type III procollagen N-terminal propeptide (PIIINP) in the serum of the exposed workers and the referents at two cut-off levels.

\begin{tabular}{|c|c|c|c|c|c|c|}
\hline \multirow{3}{*}{ Cut-off level } & \multirow{2}{*}{\multicolumn{2}{|c|}{ Referents }} & \multicolumn{4}{|c|}{ Exposed } \\
\hline & & & \multicolumn{2}{|c|}{ Group 1} & \multicolumn{2}{|c|}{ Group 2} \\
\hline & $\mathbf{N}$ & $\%$ & $\mathrm{~N}$ & $\%$ & $\mathbf{N}$ & $\%$ \\
\hline \multicolumn{7}{|l|}{ Mean +1 SD } \\
\hline $\begin{array}{l}\text { Subjects } \\
\text { not exceeding } \\
\text { Subjects }\end{array}$ & 94 & 87 & 14 & 60 & 3 & 12 \\
\hline \multirow[t]{2}{*}{ exceeding } & 14 & 13 & 10 & 40 & 25 & 88 \\
\hline & \multicolumn{6}{|c|}{ Chi square $=62.6 P<0.0001$} \\
\hline \multicolumn{7}{|l|}{ Mean +2 SD } \\
\hline $\begin{array}{l}\text { Subjects } \\
\text { not exceeding } \\
\text { Subjects }\end{array}$ & 101 & 94 & 20 & 85 & 17 & 59 \\
\hline exceeding & 7 & 6 & 4 & 15 & 11 & 41 \\
\hline & \multicolumn{6}{|c|}{ Chi square $=20.4 P<0.0001$} \\
\hline
\end{tabular}

function tests, are shown in table 4 . In the subjects with a reduced FVC (observed FVC less than $100 \%$ of the reference value), the concentration was significantly higher in respect not only to the referents $(\mathrm{P}<0.01)$, but also to the exposed workers with a normal FVC $(P<0.05)$. Similar findings were observed for the $\mathrm{FEV}_{1.0}$ values.

\section{Discussion}

Occupational exposure to low levels of asbestos fibers seems to bring about an increased synthesis of type III collagen in the lung, as reflected by an increase in the serum level of the $\mathrm{N}$-extension propeptides of procollagen III. In agreement with results reported by other authors (14), this increase was not age-related in our study, at least for the exposed workers and referents whose ages were in the range of 20-54 years. In addition tobacco smoking had no significant effect on the PIIINP level, as previously suggested by Bjermer et al (14) and Low et al (13). Moderate alcohol consumption could be ruled out as a causal factor since no difference in drinking habits was found between the exposed workers and the referents.

The increase of PIIINP in serum seems to be related to the intensity of exposure. In workers exposed to concentrations of asbestos fibers up to 0.2 fibers $/ \mathrm{ml}$, the serum PIIINP values were higher than in the reference group, while the workers exposed to fiber concentrations higher than 0.2 fibers $/ \mathrm{ml}$ showed values significantly elevated not only in comparison with those 
of the referents but also those of the less exposed workers. Furthermore in the subgroup of 21 workers for whom personal sampling was performed to estimate the individual total dose, a highly significant relationship was found between cumulative dose and the serum PIIINP concentration. These results, obtained with personal sampling data, confirm the correlation previously observed between exposure duration and PIIINP serum levels (17).

Our results do not agree with the observations of Okazaki et al (16), who failed to show significant differences between the PIIINP values of subjects with and without radiological signs of fibrosis in a group of 80 asbestos workers. However the reference group selected by these authors was made up of workers exposed to asbestos for at least 10 years, and therefore their reference group was hardly representative of the unexposed general population. Furthermore, according to our results, serum PIIINP elevation is an early sign, appearing in the first years of exposure. Interestingly enough, in the Okazaki et al study (16), increased serum PIIINP values were observed only for subjects with shorter durations of exposure. On the contrary Begin et al (15) demonstrated a significant increase of the PIIINP levels in BAL fluids of both subjects with asbestos-induced alveolitis and asbestos workers.

The observation that serum PIIINP is inversely related to FVC and $\mathrm{FEV}_{1.0}$ is in agreement with the results reported by Bjermer et al for sarcoidosis (14).

The predictive value of the early increase of serum PIINP in asbestos-exposed workers is still to be assessed. However there is little doubt that an increase in type III collagen may be associated with the first stages of an active fibrotic process as demonstrated in skin scarring (23) and alcohol hepatitis (24). In the lungs of patients with cryptogenetic fibrosing alveolitis an increased proportion of type III collagen was observed in sites of early active fibrosis (7). Similar findings have been reported for outer zones of silicotic nodules (6). By contrast in the sites of relatively acellular areas of dense fibrous tissue, such as the center of silicotic nodules, pleural plaques, and lung acellular fibrotic tissue, only type I collagen (25) was found.

Since serum PIIINP levels are related to the synthesis and deposition of type III collagen in the lung (12), the elevated levels found in the serum of our groups of workers may be the consequence of the early stage of the active fibrotic process induced by asbestos exposure. The fact that the increase was dose-dependent further supports the hypothesis. The usefulness of the determination of serum PIIINP as a biological index with which to monitor exposure to low levels of asbestos is confirmed by the data presented in table 3 , which suggests a dose-response relationship between exposure level and serum PIIINP.

Since the distribution of the PIIINP concentrations of the referents and exposed subjects was roughly nor- mal, we took two different cut-off levels for the reference values of serum PIIINP, one by adopting the mean level of PIIINP in the reference group plus the value of the standard deviation of the mean and one by taking the mean value plus twice the value of the standard deviation. As shown in table 5, the first cut-off level discriminated well between the unexposed referents and the workers exposed to more than 0.2 fibers $/ \mathrm{ml}$. The low exposure group then had $40 \%$ of its workers with an increased level of serum PIIINP and $60 \%$ with values that fell in the reference interval. With the two standard deviation level, the specificity of the test increased in parallel to the decrease in sensitivity.

Factors related to individual susceptibility are possibly of relevance to the determination of the variation in fibrogenic response, and, consequently, indicators capable of selecting susceptible subjects are particularly needed (26). If our results are confirmed in longitudinal studies, the determination of the serum level of PIIINP could represent a biological index with which to monitor subjects exposed to asbestos and, possibly, to other fibrogenic substances. If so, the possibility exists to evaluate occupational lung fibrogenic diseases at an earlier, potentially reversible, stage and to identify subjects who are more likely to develop disease.

\section{Acknowledgments}

This work was supported by a grant from EmiliaRomagna Region (delibera no 1970, 13/5/1970).

\section{References}

1. Keogh BA, Crystal RG. Alveolitis: the key to the interstitial lung disorders. Thorax 1982;37:1-10.

2. Cottino F, Bo A, Favero A, Rubino GF, Ponzetti C, Aceto G. La scintigrafia con 67-Gallio nelle pneumoconiosi. Med Lav 1985;76: 22-9.

3. Rom WN. Commentary: research on the mechanisms of the occupational lung diseases. Arch Environ Health 1984;39:186-9.

4. Forni A, Guerreri MC, Chiappino G. Nuovi metodi di indagine nelle pneumopatie professionali: il lavaggio broncoalveolare: Esperienza dell'Istituto di Medicina del Lavoro dell'Universita' di Milano. Med Lav 1985;76: $11-6$.

5. Keogh BA, Crystal RG. Clinical significance of pulmonary function tests: pulmonary function testing in interstitial pulmonary disease: what does it tell us? Chest 1980;78:856-65.

6. Bateman ED, Turner-Warwick M, Haslam PL, Adelmann-Grill BC. Cryptogenic fibrosing alveolitis: prediction of fibrogenic activity from immunohistochemical studies of collagen types in lung biopsy specimens. Thorax 1983;38:93-101.

7. Kirk JME, Heard BE, Kerr I, Turner-Warwick M, Laurent GJ. Quantitation of type I and III collagen in biopsy lung samples from patients with cryptogenic fibrosing alveolitis. Coll Relat Res 1984;4:169-82.

8. Yurui L, Xun H, Lan Y. Study of type I and III collagen changes during fibrosis induced by silica and 
welding fume dust. In: Abstracts of communications of VIIth International Pneumoconiosis Conference, Pittsburgh, 23-26 August 1988. 1988:63.

9. Barnes MJ, Morton LF, Bennett RC, Bayley AJ, Sims TJ. Presence of type III collagen in Guinea pig dermal scar. Biochem J 1976;157:263-6.

10. Rhode H, Vargas L, Hahn E, Kalbfleisch H, Brugnera M, Timpl R. Radioimmunoassay for type III procollagen peptide and its application to human liver diseases. Eur J Clin Invest 1979;9:451-9.

11. Fessler JH, Fessler LI. Biosynthesis of procollagen. Annu Rev Biochem 1978;47:129-62.

12. Kirk JME, Bateman ED, Haslam PL, Laurent GJ, Turner-Warwick M. Serum type III procollagen peptide concentration in cryptogenic fibrosing alveolitis and its clinical relevance. Thorax 1984;39:726-32.

13. Low RB, Cutroneo KR, Davis GG, Giancola MS. Lavage type III procollagen $\mathrm{N}$-terminal peptide in human pulmonary fibrosis and sarcoidosis. Lab Invest 1983;48:755-9.

14. Bjermer L, Thunell M, Hallgren R. Procollagen III peptide in bronchoalveolar lavage fluid: a potential marker of altered collagen synthesis reflecting pulmonary disease in sarcoidosis. Lab Invest 1986;55:654-56.

15. Begin R, Martel M, Desmarais Y, Drapeau G, Boileau R, Rola-Pleszczyncki M, Masse' S. Fibronectin and procollagen 3 levels in bronchoalveolar lavage of asbestos-exposed human subjects and sheep. Chest 1986;89:237-43.

16. Okazaki I, Maruyama K, Kobayashi Y, Lilis R, Suzuki Y. Serum type III procollagen peptide: indicator for pulmonary fibrosis: II. application in 80 asbestos insulation workers. Am J Ind Med 1987;11:439-46.

17. Cavalleri A, Gobba FM, Bacchella L, Luberto F, Ziccardi A. Serum type III procollagen peptide in asbestos workers: an early indicator for pulmonary fibrosis. $\mathrm{Br}$ $\mathrm{J}$ Ind Med 1988;45:818-23.
18. Asbestos International Association (AIA). Recommended technical method no 1: reference method for the determination of airborne asbestos fibre concentration at workplace by light microscopy (membrane filter method). London: AIA, 1979. (AIA health and safety publication.)

19. Finkelstein MM. A study of dose-response relationship for asbestos associated disease. Br J Ind Med 1985;42: $319-25$.

20. Cotes JE. Lung function. Oxford: Blackwell, 1979.

21. International Labour Office (ILO). Guidelines for the use of ILO international classification of radiographs of pneumoconiosis. Geneva: ILO, 1980.

22. American Conference of Governmental Industrial Hygienists (ACGIH). Threshold limit values and biological exposure indices for 1988-1989. Cincinnati, OH: ACGIH, 1988.

23. Haukipuro K, Risteli L, Kairaluoma MI, Risteli J. Aminoterminal propeptide of type III procollagen in healing wound in humans. Ann Surg 1987;206:752-6.

24. Maruyama K, Okazaki I, Shigeta Y, Ishii H, Tsuchiva $M$. Type-specific collagen-degrading enzyme activity and serum type III procollagen aminopeptide in various alcoholic liver diseases. In: Hirayama C, Kivirikko KI, ed. Pathobiology of hepatic fibrosis. Amsterdam: Excerpta Medica, 1985:131—40.

25. Bateman ED, Turner-Warwick M, Adelmann-Grill BC. Immunohistochemical study of collagen types in human foetal lung and fibrotic lung diseases. Thorax 1981; 36:645-53.

26. Polzik EV, Kogan FM, Kochneva MJ, Potanin NI. Risk factors for asbestos in workers of asbestos mills. Med Lav 1989;80:363-70.

Received for publication: 18 June 1990 